Supplement of

\title{
Climatic variations during the Holocene inferred from radiocarbon and stable carbon isotopes in speleothems from a high-alpine cave
}

Caroline Welte et al.

Correspondence to: Caroline Welte (cwelte@ phys.ethz.ch) and Jens Fohlmeister (jens.fohlmeister@ pik-potsdam.de)

The copyright of individual parts of the supplement might differ from the article licence. 


\section{S1. Anomalies in ${ }^{12} \mathrm{C}$ and $\mathrm{F}^{14} \mathrm{C}$ during LA-AMS}

An unexpected signal was observed during radiocarbon analysis by LA-AMS in the bottom piece of stalagmite SPA 127 (Fig. S1). The signal intensity (top panel of Fig. S2) is expressed as the ${ }^{12} \mathrm{C}^{-}$current recorded by the AMS. A typical signal evolution during the course of a measurement is a fast rise in the ${ }^{12} \mathrm{C}^{-}$-current to about $5 \mu \mathrm{A}$ after the laser is started, followed by a slower and steady increase to about $6-8 \mu \mathrm{A}$ (compare also Welte et al. (2016)). After 10 - 15 minutes, the maximum lifetime of the sputter target in the ion source is reached as its $\mathrm{CO}_{2}$ outlet is blocked from deposits resulting in a decrease in ${ }^{12} \mathrm{C}$ current. A new sub-scan has to be started using a fresh sputter target. In the bottom section of SPA 127, five peaks were observed in the ${ }^{12} \mathrm{C}$-current with corresponding $\mathrm{F}^{14} \mathrm{C}$ dips from approximately 0.2 down to 0.05 . The repeated scan (B2, see main text), which was performed after removal of the top surface layer, showed a similar behavior (see Figure S3). We additionally investigated the regions showing these peaks using FTIR. These anomalies are less distinctly observed in the third LA-AMS scan (Figures S2 and S3).

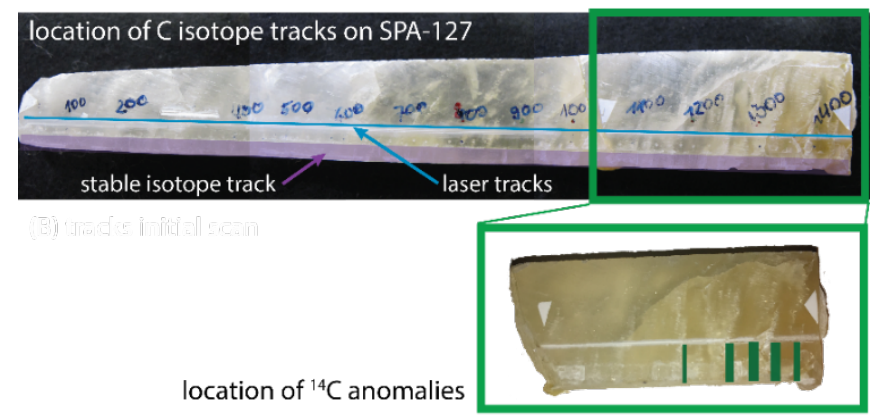

Fig. S1 Picture of stalagmite SPA 127 (top is left). Top and bottom piece (green box indicates bottom slab) with location of the stable isotope track marked in purple and LA-AMS test track in blue (the tracks corresponding to the data presented in this work were placed next to the test tracks). The total length of the slab is $14.6 \mathrm{~cm}$. The green box shows the bottom piece after removal of approximately $0.5 \mathrm{~mm}$ from the sample surface with the repeated LA-AMS laser track and approximate locations of layers exhibiting anomalies during LA-AMS (green areas).

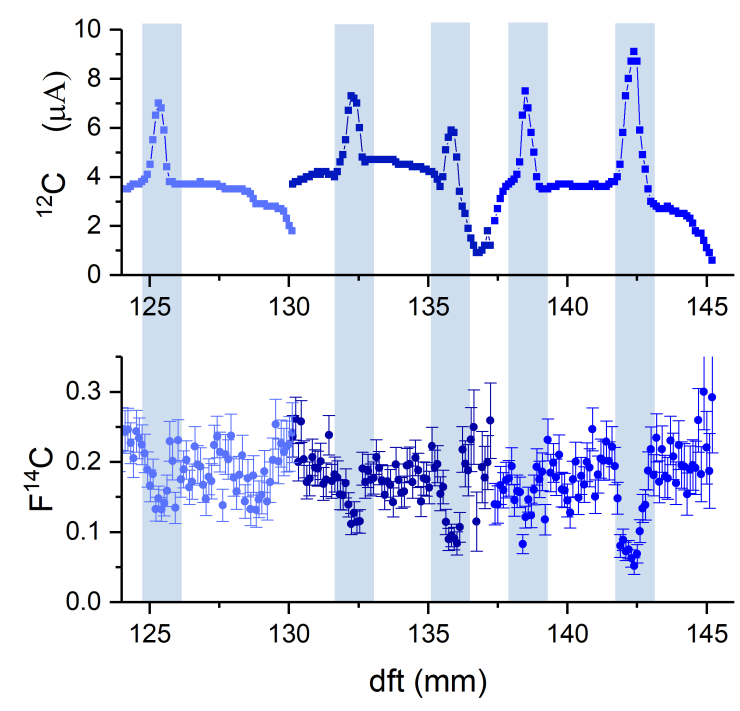

Fig. S2 Anomalies observed in the signal intensity $\left({ }^{12} \mathrm{C}\right)$ and $\mathrm{F}^{14} \mathrm{C}$ for the initial scan performed on the bottom piece. The scan consists of three sub-scans represented by the different shades of blue. At the beginning and towards the end of each subscan the ${ }^{12} C_{H E}$ current rises and drops respectively, i.e. at $130 \mathrm{~mm}, 137 \mathrm{~mm}$ and $145 \mathrm{~mm}$, which is an expected behavior. The anomalies in both measurement parameters are indicated by the blue boxes. 

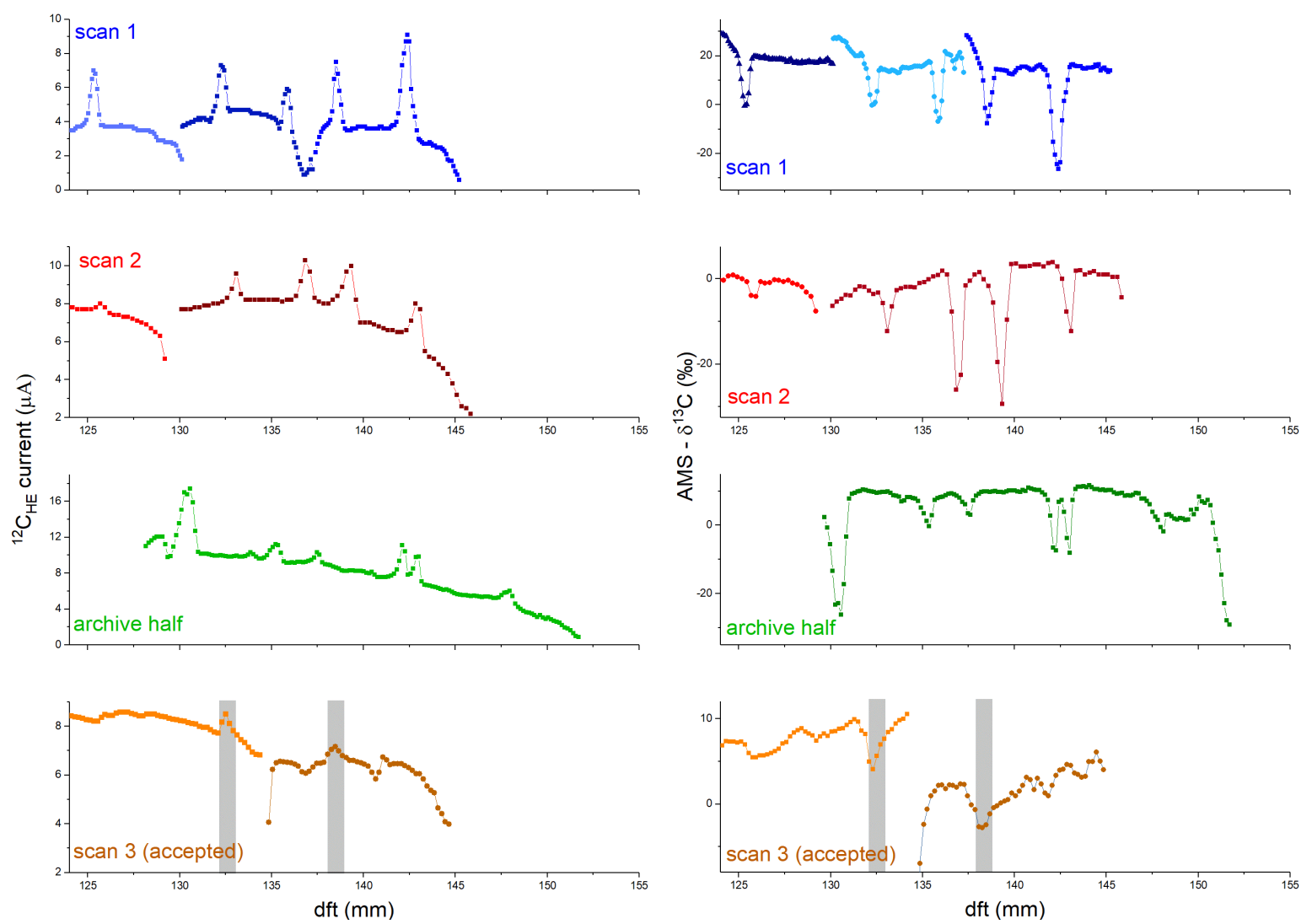

Figure S3 Left panels show the ${ }^{12} \mathrm{C}$-current of the four successive LA-AMS scans on the original and archive slab of SPA 127. Right panels show the $\delta^{13} \mathrm{C}$ measured by AMS for fractionation correction. Absolute values can differ substantially from true values. In the first three cases (scan 1, scan 2, archive half) numerous wiggles in ${ }^{12} \mathrm{C}$ and corresponding dips in $\delta^{13} \mathrm{C}$ indicate areas where epoxy was ablated. In the last scan (data selected for this manuscript), no such pronounced wiggles and dips were identified. However, two regions possibly show a slight epoxy contamination and are marked with grey bars. Different colors within each panel indicate different sputtering targets: the use of a new target and reaching the end of its maximum lifetime may have additionally altered the current and the $\delta^{13} \mathrm{C}$ values.

Interpretation of the anomlies

The five ${ }^{12} \mathrm{C}$-current peaks correlating with strongly depleted $\mathrm{F}^{14} \mathrm{C}$ observed between 120 and $145 \mathrm{~mm}$ depth, i.e. from 8.4 to $8.0 \mathrm{ka} \mathrm{BP}$, indicate that these layers are composed of a different material than the bulk. The higher ${ }^{12} \mathrm{C}$-currents are associated with a matrix that converts more readily to $\mathrm{CO} / \mathrm{CO}_{2}$ upon LA compared to $\mathrm{CaCO}_{3}$, a behavior that is known from organic substances with a higher oxygen/carbon stoichiometric ratio (Frick and Gunther, 2012). In order to ascertain whether the substance in these layers is inherent to the stalagmite or a contamination, its composition has been determined using FTIR. These measurements revealed that the anomalies were caused by epoxy resin (Fig. S4 and S5).

Indeed, the stalagmite was glued in this section when it broke into two parts shortly after its removal from the cave in 2002 CE (Fig. S6). Although the speleothem was only glued on one location, we observed the glue at least at five positions coinciding with small cracks. This suggests that the glue was able to soak through these small cracks. Hence, attention should be paid when working with glued speleothems, especially, if the type of geochemical analyses is based on methods not easily able to differentiate the analyzed material such as e.g. laser ablation IRMS (Spötl and Mattey, 2006), while e.g. IRMS based on drilled material, which is acidified by $\mathrm{H}_{3} \mathrm{PO}_{4}$, should be unaffected. 
These findings underline that unlike conventional analytical methods applied to stalagmite samples for ${ }^{14} \mathrm{C}$ analysis, which provide exclusively the isotope composition of the $\mathrm{CaCO}_{3}$, LA-AMS additionally yields the ${ }^{14} \mathrm{C}$ content of OM captured in stalagmites. Despite the fact that this offers novel possibilities it also requires particular caution to distinguish between inherent $\mathrm{OM}$ and contaminants of organic origin.

${ }^{14} \mathrm{C}$ data used for the interpretation in this study stem from scan B3, which was largely unaffected by the epoxy because the scan was placed off the glued joint as confirmed by conventional ${ }^{14} \mathrm{C}$ analysis (see Fig. A4). 


\section{S2. Fourier Transform Infrared spectroscopy (FTIR) analysis}

Fourier Transform Infrared spectroscopy (FTIR) was used to determine the specific composition of selected areas in our sample to clarify the causes of anomalies. FTIR is a standard non-invasive technique for material analysis (Derrick et al., 2000). The coupling of the IR spectrometer with a microscope enables micro-analysis, while the development of focal plane array (FPA) detectors allows to perform imaging instead of single point measurements. Attenuated total reflection (ATR) is a technique that requires no sample preparation other than a flat surface and is independent of the thickness of the sample as it is performed upon contact of the sample with the ATR crystal, which is a medium of high refractive index.

The analysis of the speleothem was performed on a Spotlight 400 FT-IR Imaging System (Perkin Elmer, Massachusetts, USA), equipped with a MCT array (mercury cadmium telluride) detector. The stalagmite was placed under the microscope on a motorized stage and focused to measure the spectrum between 4000 and $520 \mathrm{~cm}^{-1}$ using a micro-ATR objective germanium crystal at $4 \mathrm{~cm}^{-1}$ spectral resolution and 32 scans. The detection area of a measurement was $300 \times 200 \mu \mathrm{m}^{2}$ in diameter (spot size). An area of $1.9 \times 3.4 \mathrm{~mm}$ in the vicinity of the abnormal ${ }^{14} \mathrm{C} /{ }^{12} \mathrm{C}$ behavior observed by LA-AMS was selected for rastering by FTIR.

In the regions where LA-AMS anomalies were observed, two different types of matrices were revealed by the FTIR spectra (Fig. S5), representing calcite and epoxy resin. The epoxy resin spectra were found for measurement points along a crack present in this area. The calcite matrix was found in all other measurement points outside of the crack.
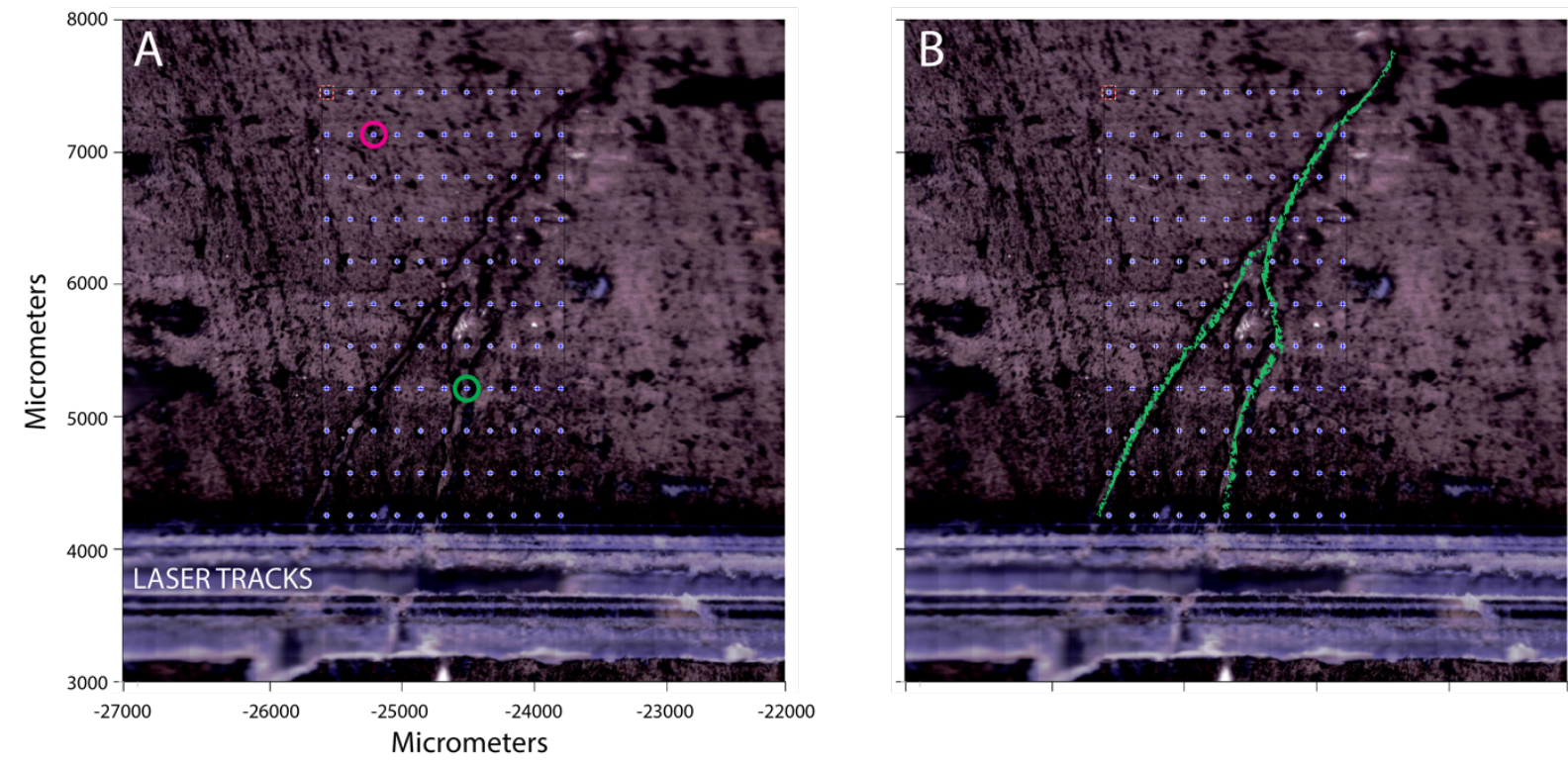

Figure S4 A) Overview of FTIR raster. Laser tracks served for orientation. The blue dots represent the measurement points. The green circle represents a measurement point within the crack, while the pink circle represents one point well away from it. B) The crack found in the area of interest (selected based on LA-AMS anomalies) is marked in green. 

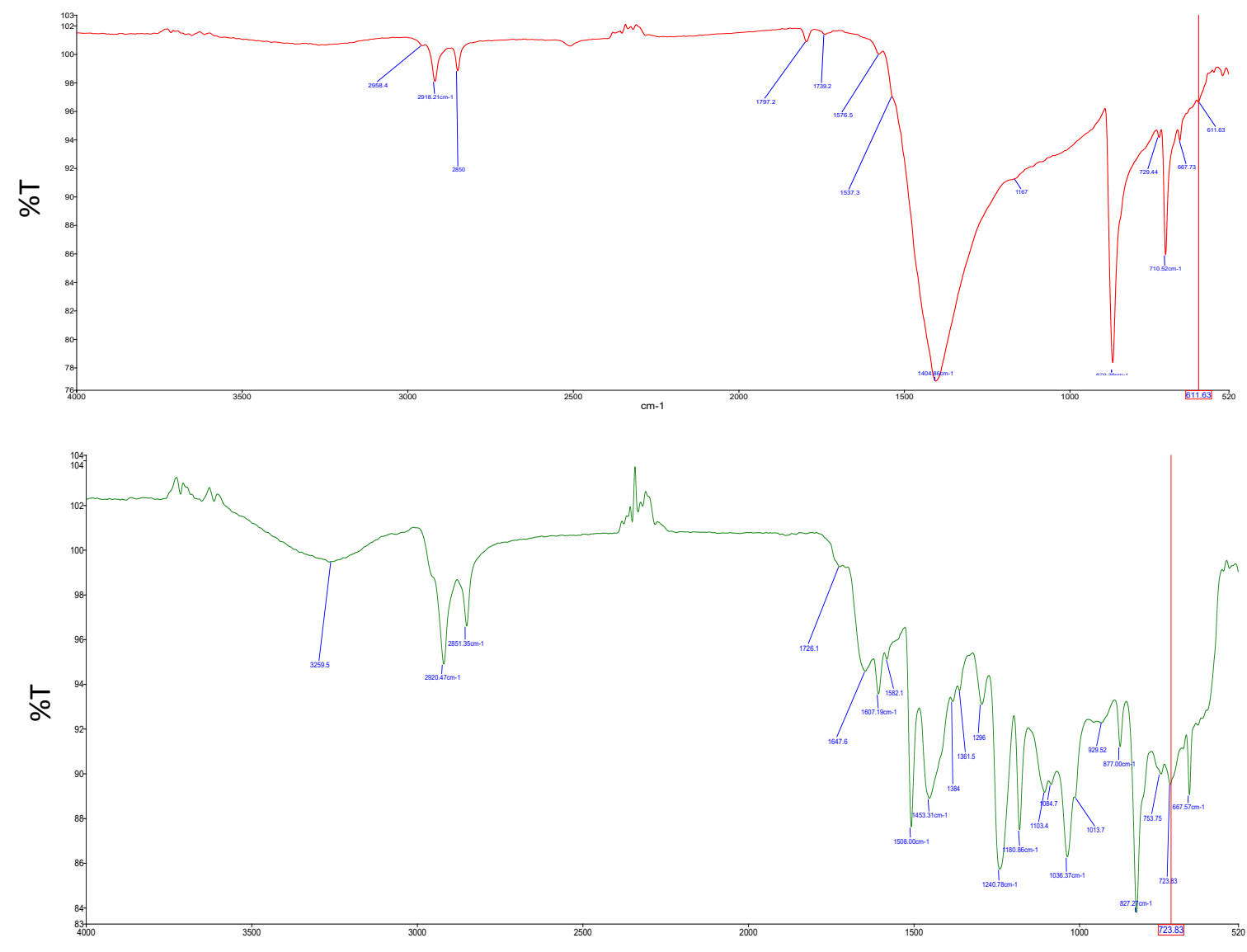

Wavenumber $\left(\mathrm{cm}^{-1}\right)$

Figure S5 Top: FTIR spectrum representative of measurements outside the crack (such as the pink circle in Figure 1 of SI) showing a calcite matrix. Bottom: FTIR spectrum representative of measurements within the crack (such as green circle in Figure 1 of SI) revealing epoxy in the matrix.
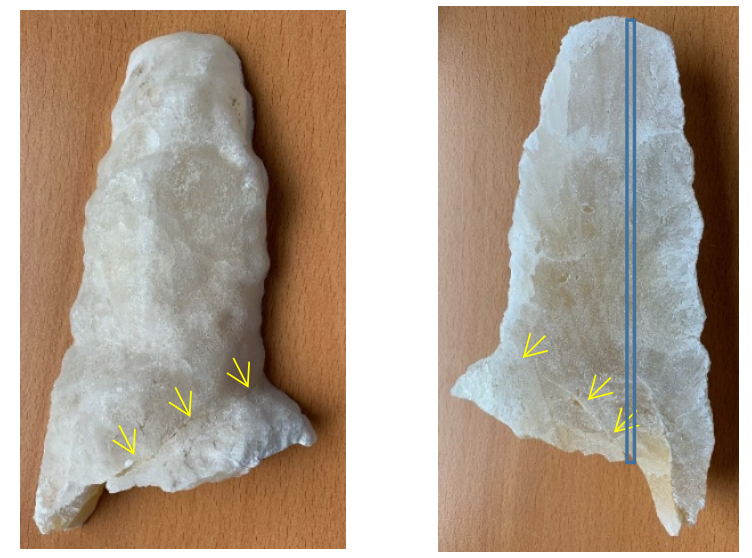

Figure S6: Images of the outside and inside of stalagmite SPA 127 with indication of the glued fracture (yellow arrows). The final scan was placed within the two blue lines (right panel), a location that is as close as possible to the central stalagmite axis but outside of the glued area. 


\section{S3. Savitzky-Golay Filter}
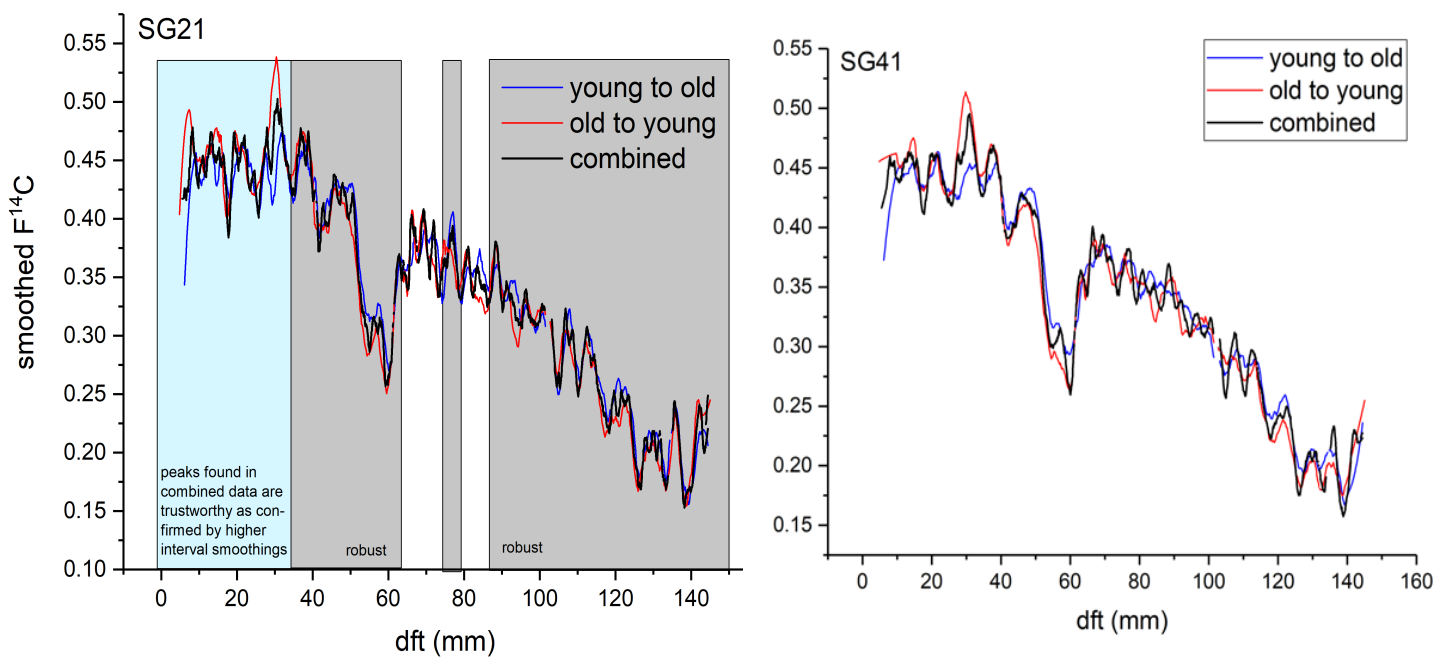

Figure S7: Left: Savitzky-Golay filter with 21 points interval length for the two individual scans (blue and red) and for the combined data (black). Grey shaded areas indicate regions of high agreement between the individual filters and hence regions where the smoothing is considered to be robust. The blue shaded area is regarded as trustworthy as well, because the pattern of the combined data is confirmed for longer interval lengths, i.e. 41 points (see right panel). 


\section{S4 LA-AMS results (raw data)}

${ }^{14} \mathrm{C}$ results are shown in Fig. S8A, where error bars are not displayed for reasons of clarity. The measured $\mathrm{F}^{14} \mathrm{C}$ ranges of both pieces of SPA 127 ( $\mathrm{T} 1, \mathrm{~T} 2$ and $\mathrm{B} 3$ ) range from about 0.55 at the top to approximately 0.15 towards the oldest part of the stalagmite. Between 0 and ca. $40 \mathrm{~mm}$, the $\mathrm{F}^{14} \mathrm{C}$ varies around a comparably constant value of 0.45 , followed by a pronounced dip between $40 \mathrm{~mm}$ and $70 \mathrm{~mm}$. From $70 \mathrm{~mm}$ to $140 \mathrm{~mm}, \mathrm{~F}^{14} \mathrm{C}$ decreases from 0.4 to 0.2 . The measurement precision is approximately $8 \%$ for the younger slab and $10 \%$ for the older piece with a spatial resolution of $280 \mu \mathrm{m}$ per data point. In Fig. S8B, $\mathrm{F}^{14} \mathrm{C}$ data is depicted in grey with uncertainties corresponding to the analytical error. In order to reduce noise a SG filter has been applied with an interval length of 21 points and the polynomial order of 2 . Stable $\mathrm{C}$ and $\mathrm{O}$ data are shown in Fig. S8 C.
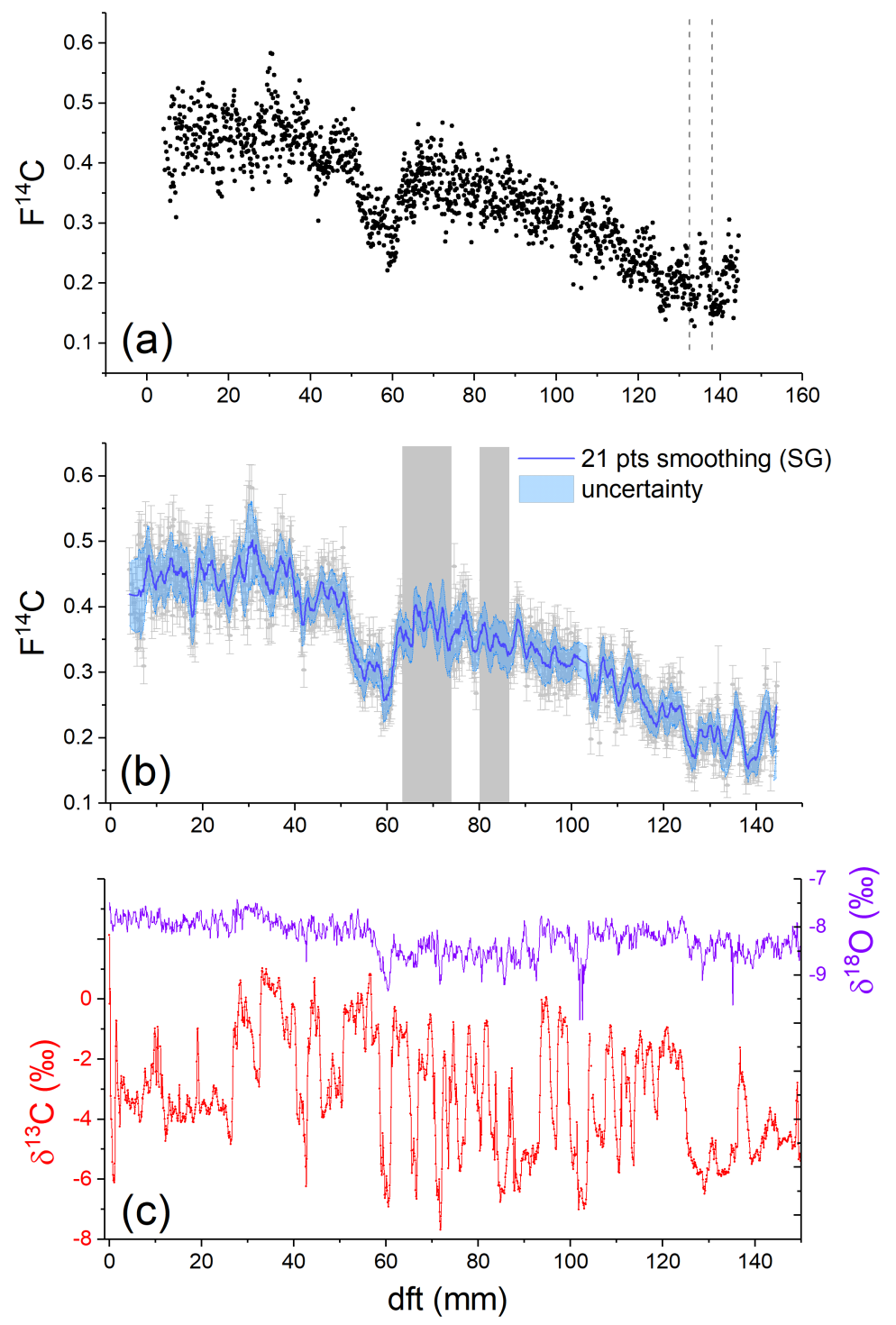

Figure S8: (A) F ${ }^{14} C$ profile of SPA 127 plotted without error bars for reasons of clarity. Grey dashed lines indicate two locations potentially contaminated by epoxy resin. (B) $\mathrm{F}^{14} \mathrm{C}$ profile including error bars corresponding to measurement precision (grey) with an overlain SG filter of 21 points interval width with a maximum polynomial degree of 2. The grey shaded areas represent depths where the quality check for the SG filter was not satisfactory (compare Fig. A1). Details can be found in the text. (C) $\delta^{13} \mathrm{C}$ and $\delta^{18} \mathrm{O}$ data of SPA 127. 


\section{S5. Conventional ${ }^{14} \mathrm{C}$ analysis by gas ion source AMS}

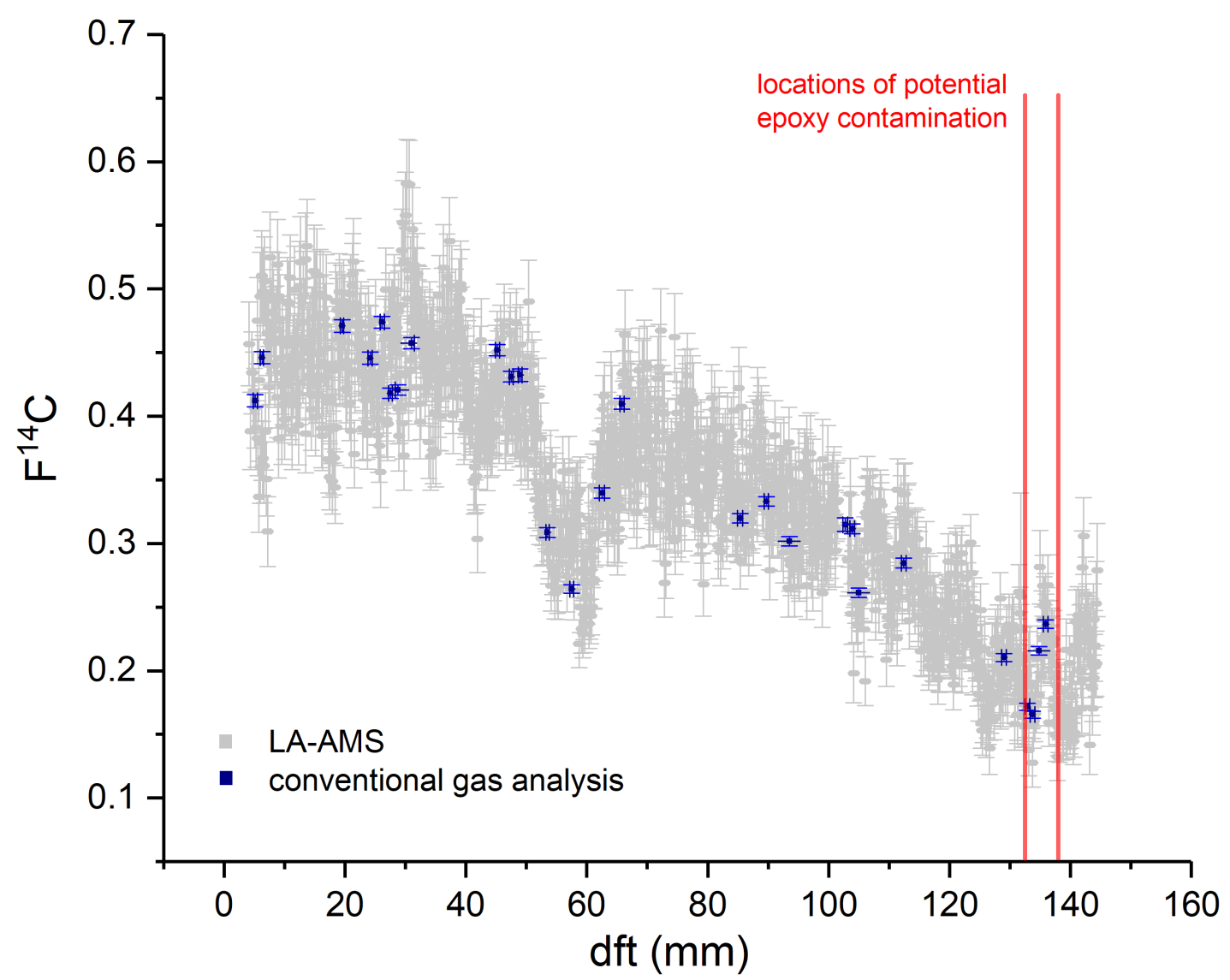

Figure S9: Comparison of LA-AMS data with conventional AMS data using a gas ion source. In short, $1-2 \mathrm{mg} \mathrm{CaCO}_{3}$ samples were analyzed following the procedure described in Wacker et al. (2013). The red lines indicate two locations that were identified as potentially contaminated by epoxy resin (see caption of Fig. 3 in SI). However, results of both methods are in good agreement, especially at a dft of $133 \mathrm{~mm}$ (first red line). At $148 \mathrm{~mm}$, epoxy contamination cannot be ruled out as no conventional data point was sampled there. However, the generally high agreement, also in the oldest part of SPA 127, suggests that the LA-AMS data are robust. 


\section{S6. Correlation test dcf, $\delta^{13} \mathrm{C}$ and $\delta^{18} \mathrm{O}$}
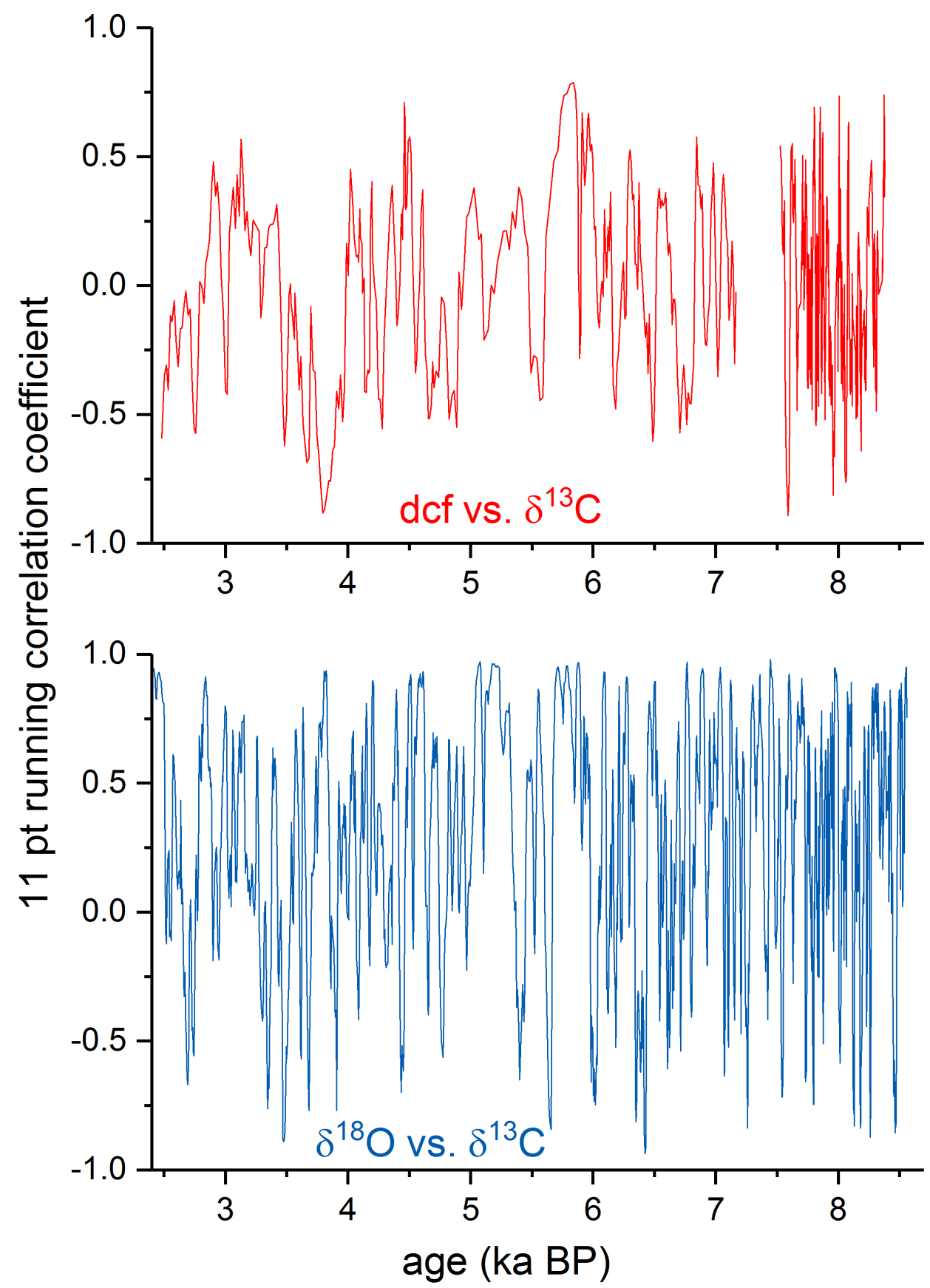

Figure S10: 11-point running correlation coefficients calculated for the dcf versus $\delta^{13} \mathrm{C}$ (top) and for $\delta^{18} \mathrm{O}$ versus $\delta^{13} \mathrm{C}$ (bottom).

\section{References}

Derrick, M. R., Stulik, D., and Landry, J. M.: Infrared spectroscopy in conservation science, Getty Publications, 2000. Frick, D. A. and Gunther, D.: Fundamental studies on the ablation behaviour of carbon in LA-ICP-MS with respect to the suitability as internal standard, Journal of Analytical Atomic Spectrometry, 27, 1294-1303, 2012.

Spötl, C. and Mattey, D.: Stable isotope microsampling of speleothems for palaeoenvironmental studies: A comparison of microdrill, micromill and laser ablation techniques, Chemical Geology, 235, 48-58, 2006. 
Wacker, L., Lippold, J., Molnar, M., and Schulz, H.: Towards radiocarbon dating of single foraminifera with a gas ion source, Nuclear Instruments \& Methods in Physics Research Section B-Beam Interactions with Materials and Atoms, 294, 307-310, 2013.

Welte, C., Wacker, L., Hattendorf, B., Christl, M., Koch, J., Synal, H. A., and Gunther, D.: Novel Laser Ablation Sampling Device for the Rapid Radiocarbon Analysis of Carbonate Samples by Accelerator Mass Spectrometry, Radiocarbon, 58, 419435, 2016. 